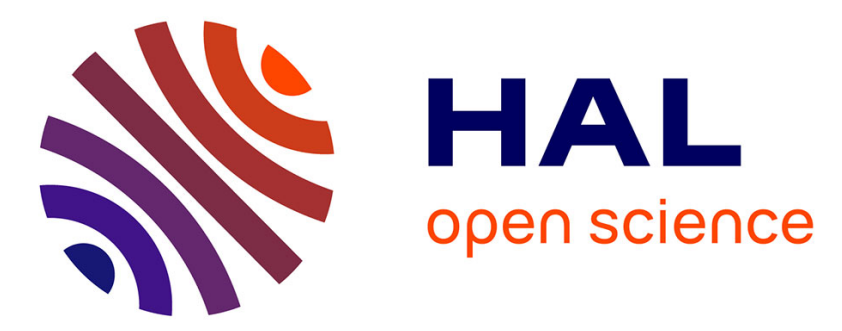

\title{
Intelligent approach based on FEM simulations and soft computing techniques for filling system design optimisation in sand casting processes
}

Ahmed Ktari, Mohamed El Mansori

\section{- To cite this version:}

Ahmed Ktari, Mohamed El Mansori. Intelligent approach based on FEM simulations and soft computing techniques for filling system design optimisation in sand casting processes. International Journal of Advanced Manufacturing Technology, 2021, pp.1-15. hal-03196668

\section{HAL Id: hal-03196668 \\ https://hal.science/hal-03196668}

Submitted on 13 Apr 2021

HAL is a multi-disciplinary open access archive for the deposit and dissemination of scientific research documents, whether they are published or not. The documents may come from teaching and research institutions in France or abroad, or from public or private research centers.
L'archive ouverte pluridisciplinaire HAL, est destinée au dépôt et à la diffusion de documents scientifiques de niveau recherche, publiés ou non, émanant des établissements d'enseignement et de recherche français ou étrangers, des laboratoires publics ou privés. 


\title{
Intelligent approach based on FEM simulations and soft computing techniques for filling system design optimisation in sand casting processes
}

\author{
Ahmed Ktari $^{1}\left(\mathbb{D} \cdot\right.$ Mohamed El Mansori $^{1,2}$ \\ Received: 5 November 2020 / Accepted: 8 March 2021 \\ (C) The Author(s), under exclusive licence to Springer-Verlag London Ltd., part of Springer Nature 2021
}

\begin{abstract}
This paper reports an intelligent approach for modeling and optimisation of filling system design (FSD) in the case of sand casting process of aluminium alloy. In order to achieve this purpose, physics-based process modeling using finite element method (FEM) has been integrated with artificial neural networks (ANN) and genetic algorithm (GA) soft computing techniques. A threedimensional FE model of the studied process has been developed and validated, using experimental literature data, to predict two melt flow behaviour (MFB) indexes named ingate velocity and jet high. Two feed-forward back-propagation ANN-based process models were developed and optimised to establish the relationship between the FSD input parameters and each studied MFB index. Both ANN models were trained, tested and tuned by using database generated from FE computations. It was found that both ANN models could independently predict, with a high accuracy, the values of the ingate velocity and the jet high for training and test data. The developed ANN models were coupled with an evolutionary GA to select the optimal FSD for each one. The validity of the found solutions was tested by comparing ANN-GA prediction with FE computation for both studied MFB indexes. It was found that error between predicted and simulated values does not exceed 5.61\% and $6.31 \%$ respectively for the ingate velocity and the jet high, which proves that the proposed approach is reliable and robust for FSD optimisation.
\end{abstract}

Keywords Filling system design · Melt flow behaviour $\cdot$ FE simulation $\cdot$ Neural networks $\cdot$ Genetic algorithm $\cdot$ Optimisation

$\begin{array}{lll}\begin{array}{ll}\text { Abbreviations } \\ \text { ANN }\end{array} & \text { Artificial neural networks } & \begin{array}{l}\text { trainlm } \\ \text { traingdx }\end{array} \\ \text { CAD } & \text { Computer-aided design } & \\ \text { FEM } & \text { Finite element method } & \text { tansig } \\ \text { FFBP } & \text { Feed-forward back-propagation } & \text { SQP } \\ \text { FSD } & \text { Filling system design } & \text { VOF } \\ \text { GA } & \text { Genetic algorithm } & \text { 3DSP } \\ \text { logsig } & \text { Log-sigmoid transfer function } & \text { LPC } \\ \text { MFB } & \text { Melt flow behaviour } & \text { EPSC-VL } \\ \text { MSE } & \text { Mean square error } & \\ \text { PSO } & \text { Particle swarm optimisation } & \\ \text { purelin } & \text { Linear transfer function } & \end{array}$

Ahmed Ktari

ahmed.ktari@ensam.eu

1 MSMP-EA7350, Arts et Métiers ParisTech, 2 cours des Arts et Métiers, 13617 Aix-en-Provence, France

2 Department of Mechanical Engineering, Texas A\&M University, College Station, TX 77840, USA

\section{Introduction}

The study of filling stage in sand casting process is of great significance since it directly affects casting quality. Inappropriate filling of castings usually generates surface oxide film entrainment that can cause $80 \%$ of the total effective casting problems [1]. Indeed, the design of filling systems is considered as a key point in sand casting, which we need to 
pay special attention, since it permits to control the melt flow behaviour (MFB) in the mould cavity. Hence, it is critical to design proper filling systems to control the liquid metal flow during the mould filling stage by reducing the velocity at ingate below the entrainment threshold $\left(0.5 \mathrm{~m} \mathrm{~s}^{-1}\right)$ [2-4].

In the past decades, several researchers have experimented with a number of parameters for design of filling systems based on the basic principles of fluid dynamics. Most of the current design knowledge on these systems are derived from trial-and-error approaches $[5,6]$, water modelling $[7,8]$ and numerical simulations [9-11].

Regarding the relative experimental difficulties encountered to visualise hot liquid metal flow in a mould and given that kinematic viscosity of most molten metals is similar to water [7, 12], numerous researchers have experimented with water models using transparent moulds made of Perspex [7] or acrylic [13]. However, to overcome the limitations of water analogs, more accurate visualisations have been realised using real-time X-ray imaging during mould filling stage $[14,15]$. However, this technique is very expensive and only offers qualitative information of the fluid flow. In addition, it demands prototype moulds that are not only expensive but also have limited geometrical flexibility that makes such techniques challenging and extremely time consuming. Indeed, in order to overcome the abovementioned drawbacks, some authors have proposed a novel qualitative method based on the use of embedded Internet of Things (IoT) sensors. This method permits to monitor the melt flow velocity in 3D sand printing (3DSP) mould during the filling stage [16] with more reasonable cost and flexibility.

In order to reduce casting defects such as gas entrapment, oxide bifilms and porosity, filling systems are typically analysed and optimised using computational modelling, statistical models and soft computing techniques like genetic algorithm (GA) or a combination of these methods [17, 18]. Jezierski et al. [19] have performed a series of computational simulations with a step-by-step modified gating system design to decrease the velocity of the metal entering the mould cavity and to reduce the possibility of bifilm creation. The direct gradient optimisation algorithm, sequential quadratic programming (SQP), has been proposed by Esparza et al. [20] to solve $2 \mathrm{D}$ and $3 \mathrm{D}$ volume of fluid (VOF) method gating system problems for two design variables. In addition, further studies have focused on the optimisation of the geometrical descriptors such as radii of the ingates and runner to minimise liquid metal velocity using evolutionary computations, viz. GA [21], Pareto front-based multiobjective optimisation [22] and a multiobjective culture-based quantum-behaved particle swarm optimisation (PSO) [23].

At the same time, some authors have focused their studies on revising conventional FSD as an alternative to the optimisation of conventional filling system [24, 25]. An offset sprue with a double perpendicular turn at the sprue/runner junction was shown as an effective solution in reducing melt turbulence [24]. However, fluid flow through double perpendicular bend is more prone to forming low-pressure vortexes at the junction that leads to oxide formation [24]. More recently, several non-conventional gating system designs have been introduced to optimise casting performance thanks to the mould design opportunities offered by 3DSP technology. In this context, Sama et al. [25] have studied the opportunity to improve the quality of castings by allowing fabrication of complex gating systems with conical helix sprue via 3DSP. They demonstrate that numerically optimised gating systems by SQP-constrained optimisation algorithm have the potential to significantly improve both mechanical and metallurgical performance of parts made by sand casting since the metal flows in a smoother way at the bottom of the sprue $[16,25]$.

Beyond sand casting process, several authors have focused their studies on the control of the MFB during the filling stage for other casting processes. For example, Bedel et al. [26] have investigated the geometrical effects on filling dynamics in low-pressure casting (LPC) process and they proposed new rules to avoid bifilm defects for making reliable LPC process. In addition, Jiang et al. [27] have studied the influence of several process parameters, viz. casting temperature, gas flow rate, vacuum level and gas pressure, on the filling ability of A356 aluminium alloy in expendable pattern shell casting process with vacuum and low pressure (EPSC-VL). These authors have found that the filling ability of A356 alloy mainly depends on the value of the gas flow rate. These authors also demonstrated, when they studied the influence of the gas flow rate on filling ability of A356 alloy in appropriate filling specimens [28], that the filling length increases with increasing the value of the gas flow rate and/or the cross-section of the filling specimen.

It is clear from the previous discussion that research in casting process has been made toward achieving nearoptimal solutions while attempting to keep the computational cost as low as possible. Trial and error methods, based on accumulated hands-on experience, are quicker and easier to implement but they do not necessarily always provide the optimal solution. Gradient-based methods provide nearoptimal designs with higher computational costs. The evolutionary computing techniques may lead us toward the optimal designs and solutions but are computationally very timeconsuming [18]. The coupling of the evolutionary GA with surrogate models, based on ANN methods, appears as a useful way to provide the optimal design with an acceptable cost.

In this work, a FE model of a conventional FSD with double perpendicular bend was developed and validated using experimental literature data. The possibility to build ANN models for predicting two different MFB indexes inside the mould cavity during the first stage of the filling process, from a set of FE computations, was tested and discussed. Then, the valid ANN models, which can act as a surrogate model, were 
coupled with a GA searching technique to optimise the values of the FSD parameters. Finally, relevance and applicability of the proposed intelligent approach, in FSD modelling and optimisation, were evaluated and discussed for each studied MFB index.

\section{FE modelling and simulation of the sand casting process}

\subsection{FE model setup}

\subsubsection{Mould design of the case study}

The conventional filling system with double perpendicular bend studied in this paper was adopted from refs. [16, 29]. The relevant dimensions of the model used in sand casting process are illustrated in Fig. 1. The design parameters $S_{\mathrm{A}}$, $S_{\mathrm{B}}, S_{\mathrm{B}}$ and $S_{\mathrm{C}}$ for the sprue, and $G_{\mathrm{E}}$ and $G_{\mathrm{F}}$ for the gate were selected as the variables of the studied FSD. All CAD models were created using CATIA ${ }^{\circledR}$ V5 5 software before being imported in the FE simulation code.

\subsubsection{Numerical modelling}

In this study, a fully coupled three-dimensional thermo-hydraulic fluid flow with phase transformation model was performed via ProCAST® FE software to simulate and analyse the melt flow inside the mould cavity during filling stage. The FE model was chosen to make numerical computations closer to the experimental conditions and to ensure that all selected combinations of FSD parameters allow a complete filling of the mould cavity (without misrun defect). The following assumptions were made in the developed model: (i) the liquid metal was incompressible Newton fluid, (ii) the filling of molten metal is a non-isothermal flow accompanied by heat transfer losses and (iii) the effect of oxide film formation is not considered.

The thermodynamic behaviour and the flow field evolution, in sand mould filling process, were modelled by the mass, momentum and energy equations as follows [30]:

Continuity equation

$\nabla \cdot u=0$

Navier-Stokes (momentum) equation

$\rho\left(\frac{\partial u}{\partial t}+(u \cdot \nabla) u\right)=\nabla \cdot \mu\left[\nabla u+(\nabla u)^{T}\right]-\nabla P+\rho g$

Energy equation

$\rho C_{\mathrm{p}} \frac{\partial T}{\partial t}=\nabla \cdot(k \nabla T)+\rho L_{\mathrm{f}} \frac{\partial f_{\mathrm{s}}}{\partial t}$

where $\rho$ is density, $t$ is time, $\mu$ is dynamic viscosity, $P$ is pressure, $g$ is gravitational acceleration component, $u$ is velocity vector, $T$ is temperature, $C_{\mathrm{p}}$ is specific heat, $k$ is thermal conductivity, $L_{\mathrm{f}}$ is latent heat and $f_{\mathrm{s}}$ is solid fraction. The equilibrium calculations at the liquid/solid interface are made by assuming an infinite diffusion in the liquid phase and no diffusion in the solid phase according to Guilliver-Scheil equation (Eq. 4) [31].

$f_{\mathrm{s}}(T)=\left\{\begin{array}{lr}0 & \text { if } T>T_{\text {liq }} \\ 1 & \text { if } T<T_{\text {sol }} \\ 1-\left(\frac{T-T_{\mathrm{f}}}{T_{\text {liq }}-T_{\mathrm{f}}}\right)^{1 /\left(k_{\mathrm{p}}-1\right)} & \text { otherwise }\end{array}\right.$
Fig. 1 CAD of the studied filling system with the variable dimensions (in red colour)

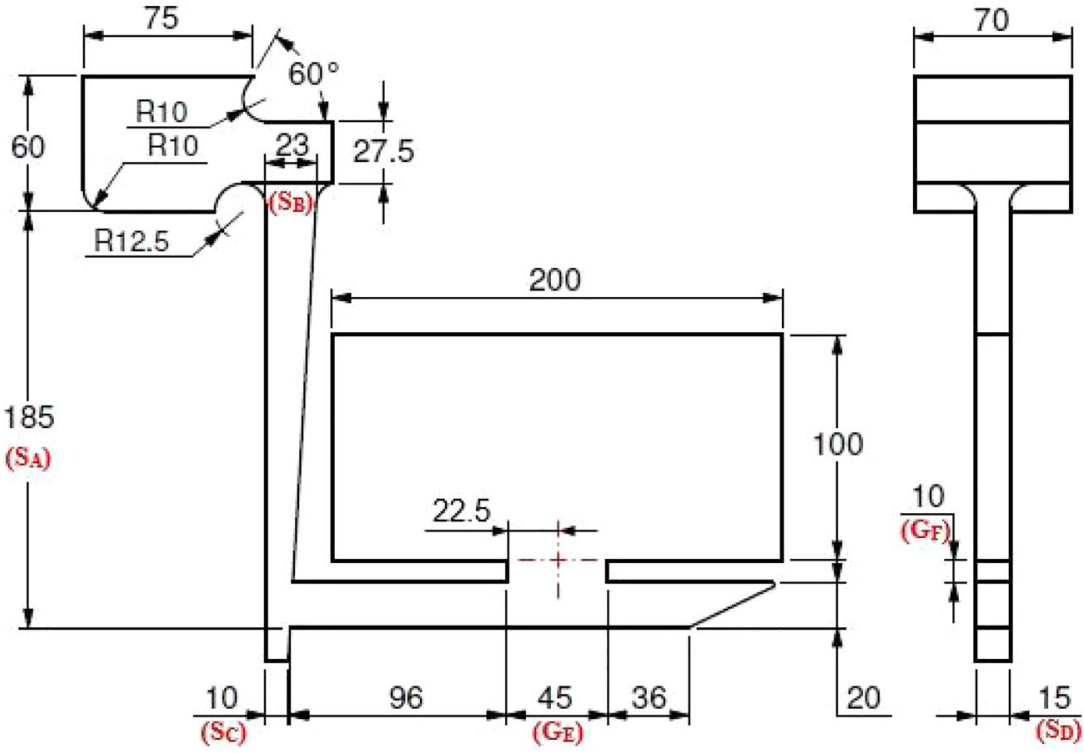


where $k_{\mathrm{p}}$ is partition coefficient, $T_{\mathrm{f}}$ is freezing temperature, $T_{\text {sol }}$ is solidus temperature and $T_{\text {liq }}$ is liquidus temperature.

Dirichlet boundary conditions are prescribed for the energy equation in the form of specified temperature values at the boundary. Natural boundary conditions take the following form $[32,33]$ :

$-k\left(\frac{\partial T}{\partial n}\right)=q+h_{\mathrm{a}}\left(T_{\mathrm{a}}-T\right)$

where $q$ is specified values of boundary heat flux, $h_{\mathrm{a}}$ is convective heat transfer coefficient (mould/air) under natural convection and $T_{\mathrm{a}}$ is ambient temperature. The liquid metal/ mould interface heat transfer is taken into account by the following equation:

$\left[-k \frac{\partial T^{\text {metal }}}{\partial n}\right]_{\text {interface }}=h_{i}\left(T^{\text {metal }}-T^{\text {mold }}\right)_{\text {interface }}$

where $n$ is the outer normal of the cast surface, $h$ is convective heat transfer coefficient at the interface, and $T^{\text {metal }}$ and $T^{\text {mold }}$ are respectively the liquid metal and the sand mould temperature.

In this study, ProCAST® FE software uses a VOF algorithm [34] to compute the location and movement of the fluid front. An order parameter $(F)$, known as a "pseudo-concentration" function $[31,35]$, having a value of unity in the fluid and zero outside is used to track the free surface position. The domain over which the Navier-Stokes equations were solved is defined by the following equation:

$\frac{\partial F}{\partial t}+(u \cdot \nabla) F=0$

During the filling stage, the fluid front is advanced within each element by solving the fluid momentum equations (Eq. 2) and, then, adjusted to satisfy mass conservation. A proprietary VOF algorithm computes the local curvature of the advancing front by assessing the degree of fill for neighbouring elements in accordance with Eq. 7. Based on this information, an adjustment to the pressure field along the free surface can be computed taking into account the effects of surface tension [36]. The coupling between mould filling and the thermal problem is achieved by solving the thermal equation (Eq. 3) using an implicit time-stepping schema at the end of each time step of the fluid momentum (Eq. 2) and advection (Eq. 7) equations, which allows one to consider the actual position of the front of the filling material. The conservation equations were solved using a fully implicit time-stepping scheme since they provide good stability and rapid convergence for very large time steps when equilibrium models are used for the evolution of the solid fraction $[37 ; 38]$. Further details of the numerical model are given in the user manual of ProCast $\AA$ [39].

\subsubsection{Mesh generation and boundary conditions}

In this model, due to the fact that problem is symmetric (geometry, material, loads and boundary conditions), only half of the problem was modelled as depicted in Fig. 2(a). The FE model was meshed using 5,689,563 linear tetrahedral elements with a mesh size of 1 and $3 \mathrm{~mm}$ respectively for the casting and the mould (Fig. 2(b)). The mesh size was selected based on mesh refinement study in order to achieve accurate solutions.

A319 aluminium alloy (Table 1) was employed in this study to make castings. The sand moulds, initially at room temperature, were poured with the molten metal at $750{ }^{\circ} \mathrm{C}$. At this temperature, the density and the kinematic viscosity of the melt are $2488 \mathrm{~kg} \mathrm{~m}^{-3}$ and $0.510^{-6} \mathrm{~m}^{2} \mathrm{~s}^{-1}$ respectively [40]. An inlet metal flow rate of $0.3 \mathrm{~kg} \mathrm{~s}^{-1}$ into the pouring basin was maintained constant during the filling stage [25]. The casting was cooled to room temperature in air with a convection coefficient of $10 \mathrm{~W} \mathrm{~m}^{-2}{ }^{\circ} \mathrm{C}^{-1}$ applied to all exterior mould surfaces. In addition, a heat transfer coefficient of $350 \mathrm{~W} \mathrm{~m}^{-2}{ }^{\circ} \mathrm{C}^{-1}$ was applied at the metal/mould interface [41].
Fig. 2 Problem modelling: (a) $\mathrm{CAO}$ of the casting and the sand mould, and (b) FE mesh

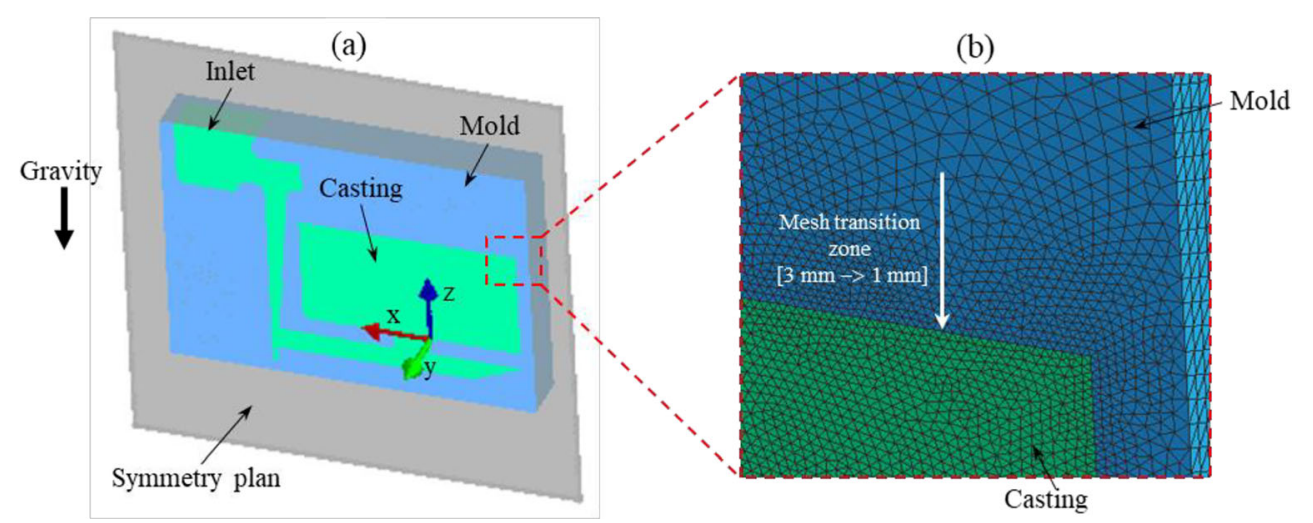


Table 1 Chemical composition of A319 aluminium alloy in wt\%

\begin{tabular}{lccccccl}
\hline Element & $\mathrm{Si}$ & $\mathrm{Cu}$ & $\mathrm{Zn}$ & $\mathrm{Ni}$ & $\mathrm{Mn}$ & $\mathrm{Mg}$ & $\mathrm{Al}$ \\
\hline $\mathrm{wt} \%$ & 5 & 3 & 1 & 0.35 & 0.4 & 0.1 & Remainder
\end{tabular}

\subsection{FE model validation}

In this paper, the FE model presented above was validated by comparing simulation results to experimental ones. The validation process includes two steps. The first one was done using the benchmark test designed by Sirrell et al. [29] to verify the interface shape evolution of the melt flow inside the mould cavity, during filling stage, from qualitative point of view. Nevertheless, for quantitative validation, the melt flow velocity inside the mould cavity was compared with experimental local measurements using appropriate sensors [16].

\subsubsection{Qualitative validation}

Concerning the aluminium alloy benchmark test, the casting is a plate made from pure aluminium with a conventional bottom-gated running system in the mould made of resin- bonded sand. A metal charge of $2.2 \mathrm{~kg}$ was poured into the pouring basin. The basin was full when filled to a depth of precisely $40 \mathrm{~mm}$. At this instant, the stopper was lifted out of the basin, beginning the filling of the sprue with the liquid metal at a temperature of $700{ }^{\circ} \mathrm{C}$ approximately. At this temperature, the density and the kinematic viscosity of the melt are $2364 \mathrm{~kg} \mathrm{~m}^{-3}$ and $0.5210^{-6} \mathrm{~m}^{2} \mathrm{~s}^{-1}$ respectively [42]. More details about the experimental conditions and parameters are presented in ref. [29].

The simulation of the experimental test was performed via the developed FE model described in Section 2.1 after adapting it to take into account the corresponding geometry and boundary conditions. Figure 3 shows the progressive interface shape evolution of the benchmark test observed during the filling process for both experimental (recorded by in situ X-ray imaging technology) and simulation results. Figure $3 \mathrm{c}$ shows the jet fountaining away from the sprue when metal enters from ingate in FE simulation which is in close agreement to real-time $\mathrm{X}$-ray radiographic observations shown in the case of aluminium castings [24, 29]. It is clear that FE simulation is in a good qualitative agreement with experimental observations. The small difference observed can be attributed to the slight variation in the values of thermo-physical properties, viz. density and kinematic viscosity between A319

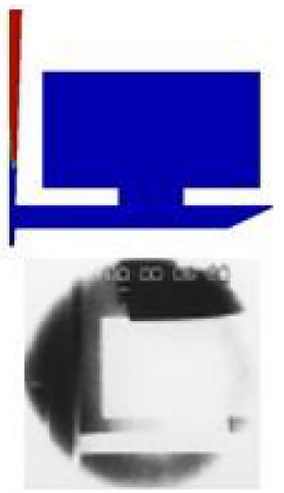

(a) Time $=0.24 \mathrm{~s}$

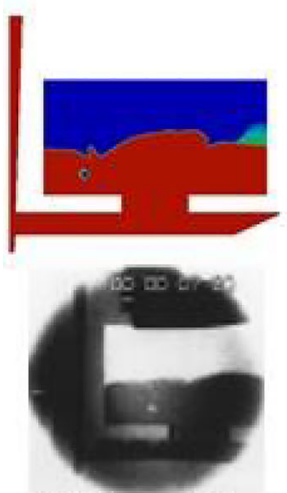

(e) Time $=1.24 \mathrm{~s}$

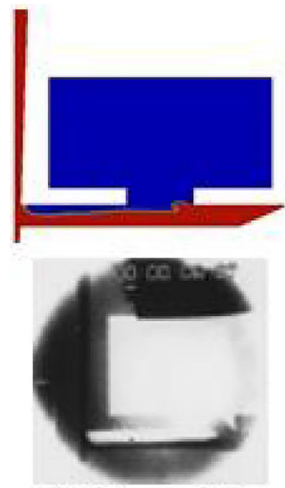

(b) Time $=0.5 \mathrm{~s}$

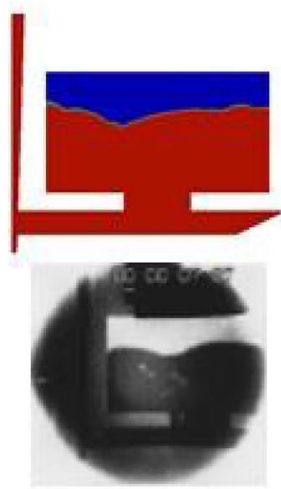

(f) Time $=1.5 \mathrm{~s}$

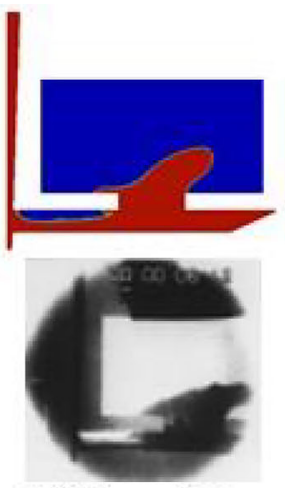

(c) Time $=0.74 \mathrm{~s}$

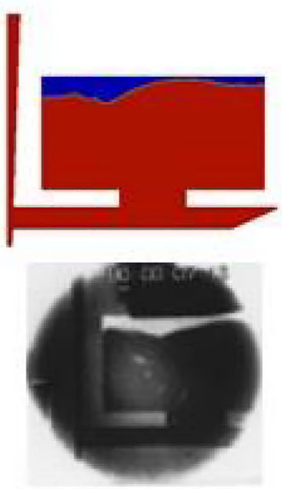

(g) Time $=1.74 \mathrm{~s}$

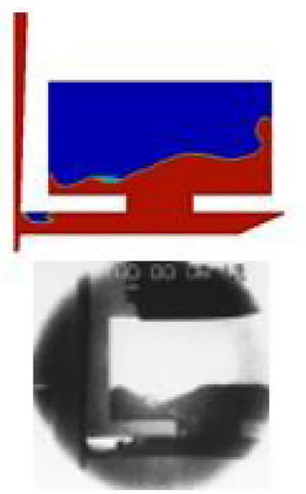

(d) Time $=1 \mathrm{~s}$

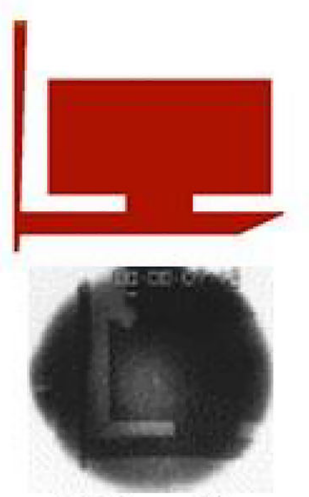

(h) Time $=2 \mathrm{~s}$

\section{Fraction \\ Volume of \\ Liquid (FVOL)

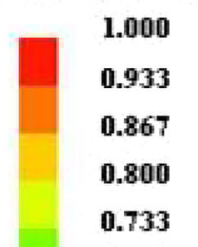

0.667

0.600

0.533

0.467

0.400

0.333

0.267

0.200

0.133

0.067

0.000

Fig. 3 FE computation versus experiment of the progressive interface shape evolution during the mould filling: a $0.24 \mathrm{~s}$ after stopper removal, b $0.5 \mathrm{~s}$, c $0.74 \mathrm{~s}, \mathbf{d} 1 \mathrm{~s}, \mathbf{e} 1.24 \mathrm{~s}, \mathbf{f} 1.5 \mathrm{~s}, \mathbf{g} 1.74 \mathrm{~s}$ and $\mathbf{h} 2 \mathrm{~s}$ 
used in FE model and pure aluminium. Here, it was found that the impact of the chemical composition on density and kinematic viscosity, considered as the most important thermophysical properties that can affect the mould filling ability of the melt, is negligible.

\subsubsection{Quantitative validation}

Concerning the quantitative validation, the FE results were compared to experimental values found by Sama et al. [16]. The experiment was performed by incorporating sensors into 3D-printed mould for sand casting process. Two dialog IoT sensors, separated by $102 \mathrm{~mm}$ along the runner, were embedded into predefined slots introduced into the Furan resin-bounded sand mould to calculate the melt average speed in the runner. Aluminium 319 was poured into the mould at $750{ }^{\circ} \mathrm{C}$ to make castings. More details about the casting dimensions and the process parameters are given in ref. [16].

Figure 4 shows the FE simulation results of the melt front during the filling process at both sensor positions. The average value of the melt velocity calculated by FE model is $1.26 \mathrm{~m}$ $\mathrm{s}^{-1}$, which is considered as very close to the experimental one $\left(1.27 \mathrm{~m} \mathrm{~s}^{-1}\right)$. This result proves that proposed FE model can predict with a high accuracy the melt flow velocity in the runner for conventional filling systems.

As a result, and in view of both qualitative and quantitative validation studies performed above, the developed FE model was approved since it can predict the MFB during the filling stage in sand casting process. Indeed, this model was retained to simulate the melt flow in the mould cavity for a combination of FSD parameter values.

\subsection{Database generation and description}

In sand casting process, the number of FSD parameters that can influence the MFB in the mould cavity is relatively large [43] which make the computation of all combinations of the studied FSD parameters, viz. $S_{\mathrm{A}}, S_{\mathrm{B}}, S_{\mathrm{C}}, S_{\mathrm{D}}, G_{\mathrm{E}}$ and $G_{\mathrm{F}}$ (see Fig. 1), impractical and difficult (i.e. performing casting computations by varying one-factor-at-a-time is cost intensive). Consequently, sampling techniques can be an alternative to cover the entirely experimental space with an acceptable cost [44] that usually permits to ensure good generalisation for the ANN model after training phase. Currently, there are multitude of sampling methods available in literature to explore the experimental space, such as stratified sampling, probability sampling and sequential sampling as Taguchi method [45-47]. Taguchi's orthogonal arrays are recognised to be useful in evaluating a small number of sample points considering interaction between the studied variables [48]. Hence, Taguchi orthogonal array $\left(L_{25}\right)$ was applied in this work to generate the different training cases for the ANN-based surrogate model. In addition, five additional cases were added to the database for testing the generalisation and ANN model. All studied FSD parameter combinations and their corresponding ingate velocity and jet high values are summarised in Table 2.

In this study, identical inlet fluid, boundary conditions and mesh dimensions were applied for all simulation cases, to determine the two MFB indexes as shown in Fig. 5. Given the high velocity gradient of the ingate melt outflow depicted in Fig. 5(a), several virtual probes were placed on the melt near the ingate top surface. Then, the average value of the measured ingate velocity was calculated according to Fig. 5(b). The determination of the jet high is simpler since it consists of measuring the distance between the

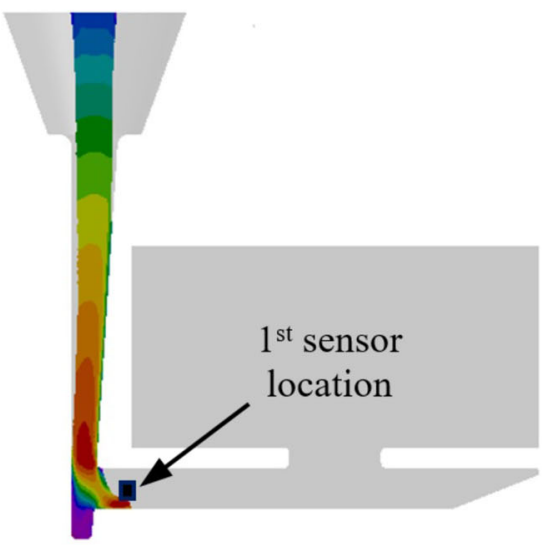

Time $=0.264 \mathrm{~s}$

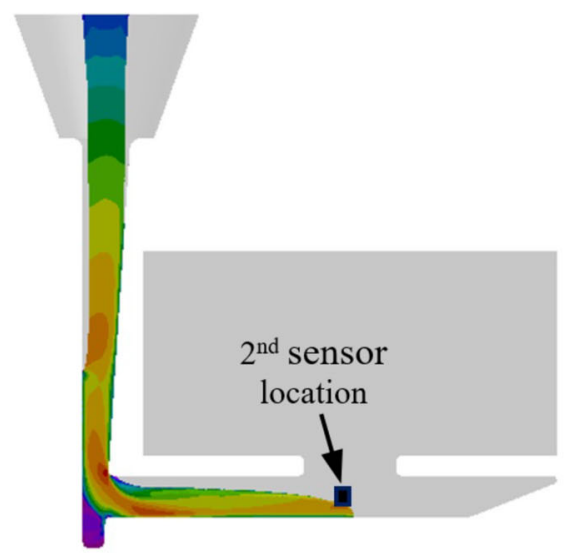

Time $=0.345 \mathrm{~s}$

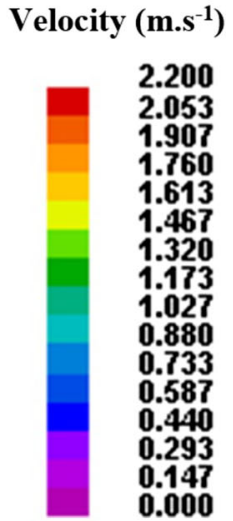

2.200

2.053

760

1.613

.467

1.027

0.880

.733

0.440

0.000

Fig. 4 FE simulation of the melt front position during the runner filling 
Table 2 The FSD parameter combination and their corresponding MFB indexes

\begin{tabular}{|c|c|c|c|c|c|c|c|c|c|}
\hline & \multirow{2}{*}{$\begin{array}{l}\text { Data } \\
\text { case no. }\end{array}$} & \multicolumn{4}{|c|}{ Sprue } & \multicolumn{2}{|c|}{ Gate } & \multirow{2}{*}{$\begin{array}{l}\text { Ingate velocity } \\
\left(\mathrm{m} \mathrm{s}^{-1}\right)\end{array}$} & \multirow{2}{*}{$\begin{array}{l}\text { Jet high } \\
(\mathrm{mm})\end{array}$} \\
\hline & & $S_{\mathrm{A}}$ & $S_{\mathrm{B}}$ & $S_{\mathrm{C}}$ & $S_{\mathrm{D}}$ & $G_{\mathrm{E}}$ & $G_{\mathrm{F}}$ & & \\
\hline \multirow{25}{*}{$\begin{array}{l}\text { Training data (train }+ \\
\text { validation) }\end{array}$} & 1 & 155 & 19 & 5 & 12 & 35 & 5 & 0.93 & 32.82 \\
\hline & 2 & 155 & 21 & 7.5 & 14 & 40 & 7.5 & 1.17 & 42.15 \\
\hline & 3 & 155 & 23 & 10 & 16 & 45 & 10 & 1.44 & 55.76 \\
\hline & 4 & 155 & 25 & 12.5 & 18 & 50 & 12.5 & 1.48 & 57.98 \\
\hline & 5 & 155 & 27 & 15 & 20 & 55 & 15 & 1.56 & 64.85 \\
\hline & 6 & 170 & 19 & 7.5 & 16 & 50 & 15 & 1.22 & 54.30 \\
\hline & 7 & 170 & 21 & 10 & 18 & 55 & 5 & 1.54 & 62.89 \\
\hline & 8 & 170 & 23 & 12.5 & 20 & 35 & 7.5 & 1.48 & 61.69 \\
\hline & 9 & 170 & 25 & 15 & 12 & 40 & 10 & 1.34 & 52.04 \\
\hline & 10 & 170 & 27 & 5 & 14 & 45 & 12.5 & 1.29 & 43.65 \\
\hline & 11 & 185 & 19 & 10 & 20 & 40 & 12.5 & 1.57 & 68.33 \\
\hline & 12 & 185 & 21 & 12.5 & 12 & 45 & 15 & 1.19 & 53.22 \\
\hline & 13 & 185 & 23 & 15 & 14 & 50 & 5 & 1.54 & 57.73 \\
\hline & 14 & 185 & 25 & 5 & 16 & 55 & 7.5 & 1.31 & 45.71 \\
\hline & 15 & 185 & 27 & 7.5 & 18 & 35 & 10 & 1.60 & 66.29 \\
\hline & 16 & 200 & 19 & 12.5 & 14 & 55 & 10 & 1.33 & 45.39 \\
\hline & 17 & 200 & 21 & 15 & 16 & 35 & 12.5 & 1.55 & 70.82 \\
\hline & 18 & 200 & 23 & 5 & 18 & 40 & 15 & 1.35 & 55.52 \\
\hline & 19 & 200 & 25 & 7.5 & 20 & 45 & 5 & 1.65 & 65.52 \\
\hline & 20 & 200 & 27 & 10 & 12 & 50 & 7.5 & 1.45 & 56.12 \\
\hline & 21 & 215 & 19 & 15 & 18 & 45 & 7.5 & 1.75 & 73.16 \\
\hline & 22 & 215 & 21 & 5 & 20 & 50 & 10 & 1.42 & 62.92 \\
\hline & 23 & 215 & 23 & 7.5 & 12 & 55 & 12.5 & 1.24 & 50.46 \\
\hline & 24 & 215 & 25 & 10 & 14 & 35 & 15 & 1.55 & 70.94 \\
\hline & 25 & 215 & 27 & 12.5 & 16 & 40 & 5 & 1.80 & 69.67 \\
\hline \multirow[t]{5}{*}{ Test } & 26 & 155 & 19 & 5 & 12 & 35 & 15 & 0.87 & 31.18 \\
\hline & 27 & 170 & 25 & 7.5 & 14 & 45 & 10 & 1.35 & 47.32 \\
\hline & 28 & 185 & 21 & 10 & 18 & 55 & 5 & 1.69 & 68.41 \\
\hline & 29 & 200 & 27 & 12.5 & 20 & 50 & 12.5 & 1.67 & 75.14 \\
\hline & 30 & 215 & 23 & 15 & 16 & 40 & 7.5 & 1.63 & 71.68 \\
\hline
\end{tabular}

ingate top surface and the highest point that jet can reach (Fig. 5(c)).

An overview of the flow velocity mapping of the molten metal captured during the filling process, for all studied cases, at the highest value that melt jet can reach is shown in Fig. 6. It is clear that most jets obtained for the studied cases fountain away from the sprue which proves that melt flow is turbulent except the case nos. 1 and 26, i.e. the melt flow behaviour seems near laminar flow conditions. For turbulent flow, when the mixing between streams is assumed as complete, the reflected wave compressed in the end of the runner experiences momentum only from the direction of the sprue. Then, as soon as the reflected wave reaches the gate, it expands rapidly into the gate, and, with momentum from the direction of the sprue, the jet fountains to the right [29].
Figure 7 shows that the variation of the jet high versus the ingate velocity can be followed by a power law with a value of correlation coefficient $R=0.934$. In addition, the extrapolation of the power law to the ingate velocity threshold $\left(0.5 \mathrm{~m} \mathrm{~s}^{-1}\right)$ indicates that the value of the jet high is $15.14 \mathrm{~mm}$. This value is very close to the natural sessile drop height value of aluminium liquid metal reported in literature (about $13 \mathrm{~mm}$ ) [49]. This result confirms once more the consistency of the built FE model and the highly significance of the chosen MFB indexes in rheological characterisation of the melt flow inside the mould cavity. Thus, both MFB indexes were monitored during the filling process to study the ability to build ANN-based surrogate models allowing the prediction of the melt flow behaviour, and then the optimisation of the FSD parameters. 


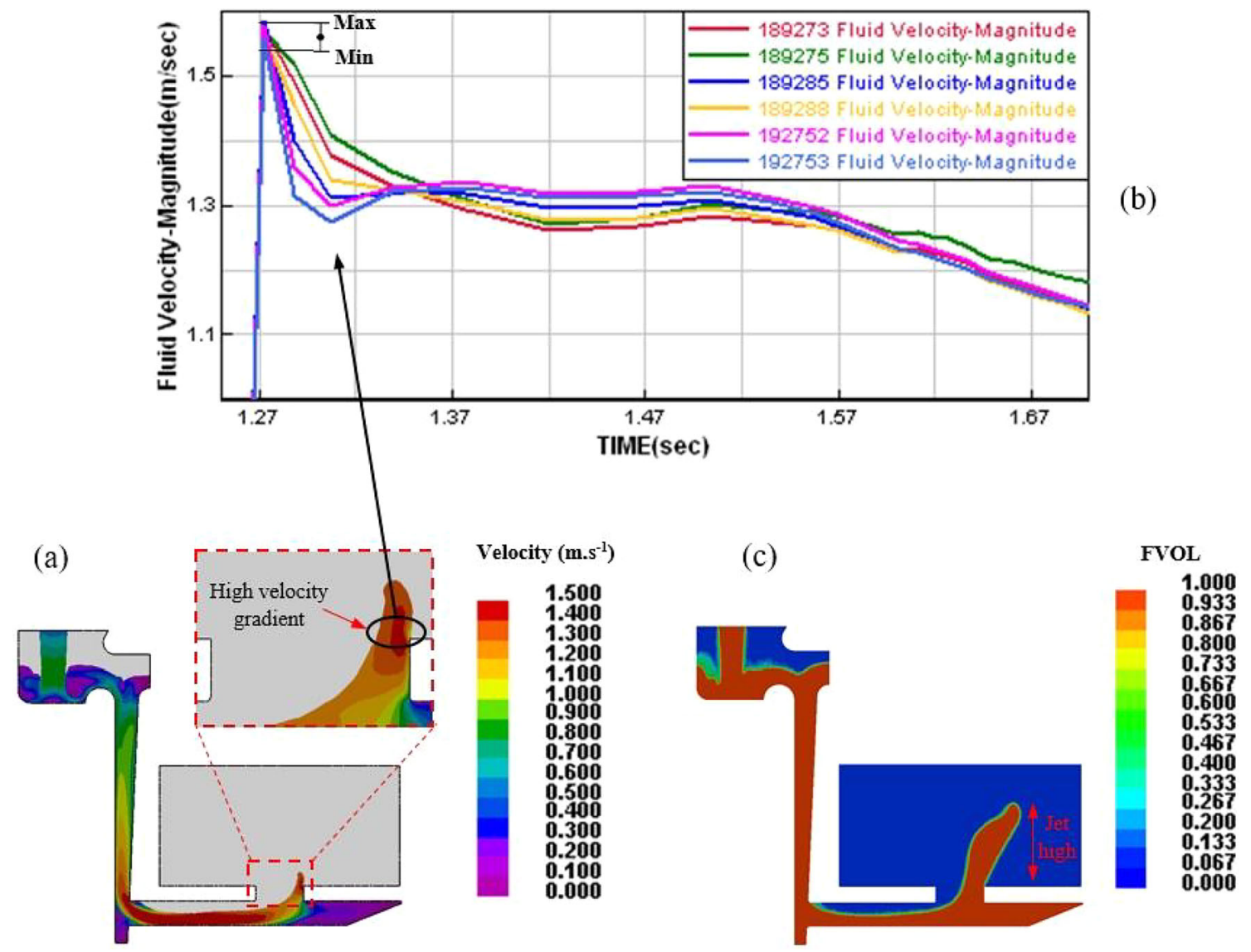

Fig. 5 The numerical results obtained from the case no. 11: (a) ingate velocity $\left(\mathrm{m} \mathrm{s}^{-1}\right)$, (b) nodal velocities of the melt near the gate top surface and (c) jet high $(\mathrm{mm})$ calculation

\section{Soft computing for FSD optimisation}

\subsection{ANN model development}

The application of ANN as a prediction tool by a wide range of industrial fields has been on the increase, due to their capability to make use of learning algorithm and recognise input/ output relationship for non-linear complex process. However, its accuracy depends on some factors as the structure of the network [50] (i.e. the number of the hidden layers and neurons in each layer) and the learning algorithm used in training phase [51, 52]. Since several training algorithms are used in neural network applications, it is difficult to predict the best one in terms of accuracy for a given problem. A number of factors, including the complexity of the problem, the number of datasets used in training and the number of weights and biases in the network, seem to have an influence [53]. Indeed, two different back-propagation training algorithms, viz. Levenberg-Marquardt (trainlm) and Gradient descent with momentum and adaptive learning rate (traingdx), were applied in this study to test their performances for several numbers of neurons in the hidden layer ranged from 4 to 20 . The development of the neural network architecture was performed using Matlab® $8.2\left(\right.$ R2013 $\left.{ }^{\mathrm{b}}\right)$ software.
In order to optimise the ANN topology, the data presented in Table 2 were divided in three sets. The first twenty cases' data ( $70 \%$ of the total data) were used to train the ANN by computing the gradient and updating the network weights and biases. The next five cases' data ( $15 \%$ of the total data) were used for validation. The error on the validation set was monitored during the training process. The validation error usually decreases during the initial phase of training. Then, once the network begins to over fit the data, the training is stopped and the network weights and biases were saved at the minimum of the validation set error. This is known as the early stopping method. The last dataset (15\% of the total data) was not involved in the training phase; however, it is useful for testing ANN model generalisation capability.

Prior to any ANN training process and in order to cancel the difference between input values, the data must be normalised over the range $[0-1]$ to reach a faster training phase and reduce the probability of being stuck in local minima. The method used in this paper was min-max scaling (Eq. 8).

$x_{i}=\frac{x-x_{\min }}{x_{\max }-x_{\min }}$

where $x_{\max }$ and $x_{\min }$ are the maximum and minimum number of data and $x_{i}$ is the normalisation value of the data $i$. 

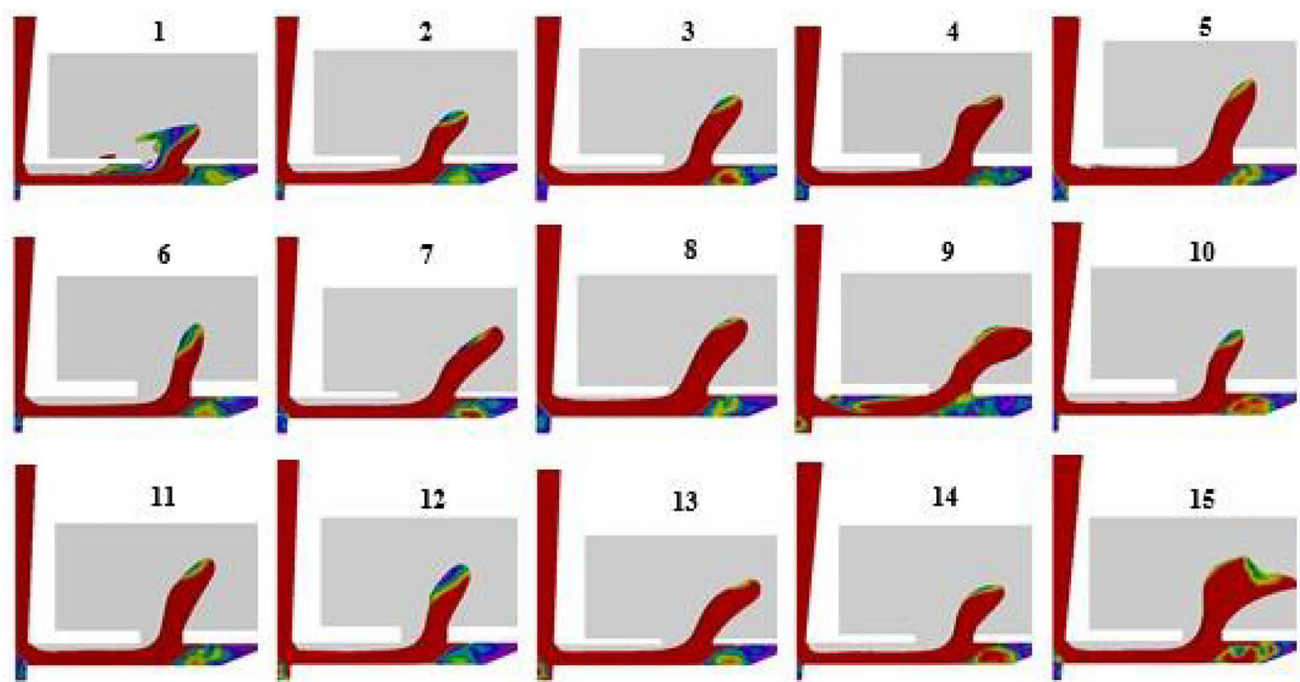

Velocity

$\left(\mathrm{m}, \mathrm{s}^{-1}\right)$
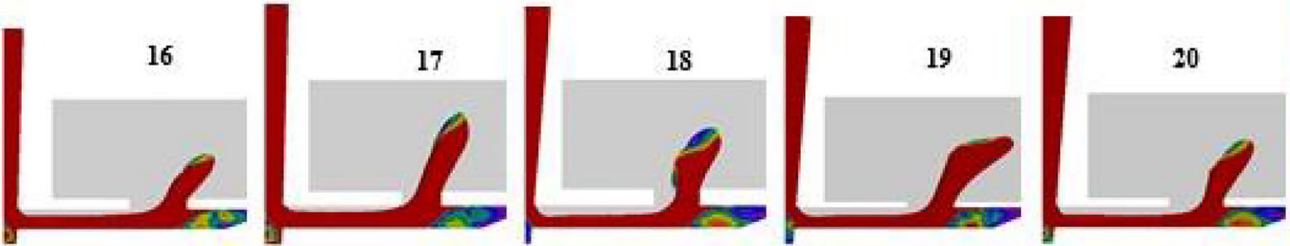

0.500

0.467

0.433

0.400

0.367

0.333

0.300

0.267

0.233

0.200
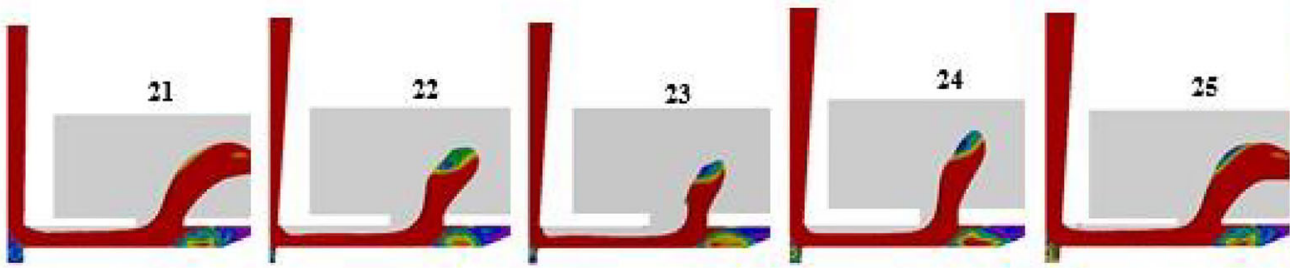

0.167

0.133

0.100

0.067

0.033

0.000
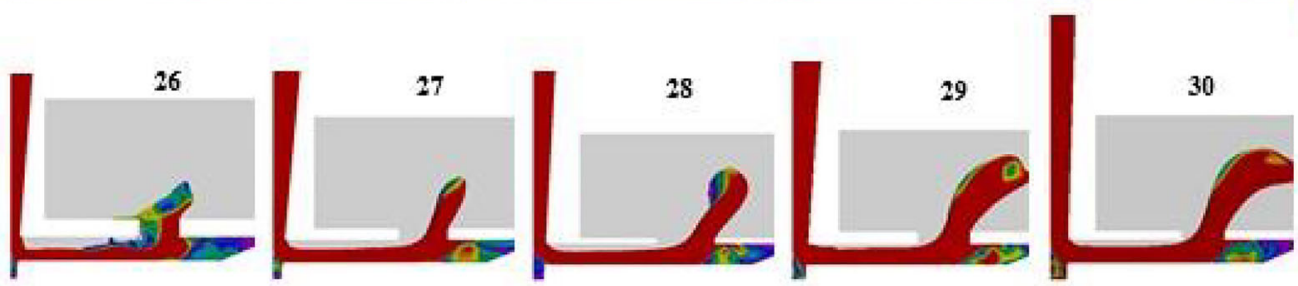

Fig. 6 Flow velocity mapping of the molten metal captured in the filling stage for all studied FSD cases at the highest value of the melt jet

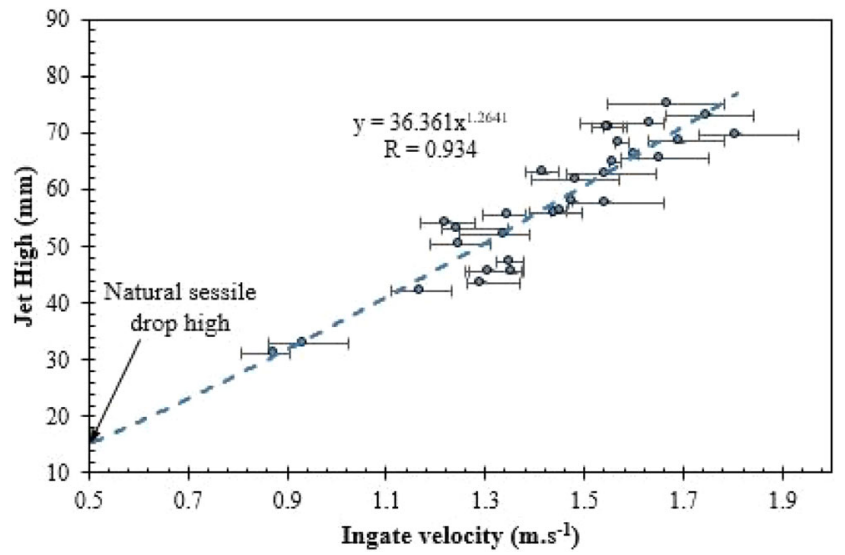

Fig. 7 Ingate velocity versus jet high in the first phase of the filling stage
During the training phase, the normalised input data values were fed to the input nodes in a feed-forward back-propagation (FFBP). Then, a hidden layer node, the function of which is to intervene between the external input and the network output, adds up the weighted input $(w)$ received from each input data associated it with a bias (b) according to Eq. 9 and then passes the result (Sum) on the nodes of the next hidden layer or the output, through transfer function.

$\operatorname{Sum}=\sum_{i=1}^{n} x_{i} w_{i}+b$

The most commonly used transfer functions to solve regression problems are tangent sigmoid "tansig" (Eq. 10), log-sigmoid "logsig" (Eq. 11) and linear "purelin" (Eq. 12) [54]. In this study, the performance of the models with 
different transfer function combinations will be discussed in the Section 4.2 .

$\operatorname{tansig}($ Sum $)=\frac{\exp (\text { Sum })-\exp (- \text { Sum })}{\exp (\text { Sum })+\exp (- \text { Sum })}$

$\log \operatorname{sig}($ Sum $)=\frac{\exp (\text { Sum })}{1+\exp (- \text { Sum })}$

$\operatorname{purelin}(\operatorname{Sum})=$ Sum

The learning process works in small iterative steps. The output is compared to the known output data values, and error is calculated. After that, small changes are made to the weights and bias in each layer in order to reduce the error. This cycle is repeated until the mean square error (MSE) value begins to over fit the data as explained above. In this study, the MSE and the correlation coefficient $(R)$, calculated respectively according to Eqs. 13 and 14, were used as criteria to compare the performances of different ANN architectures.

$\mathrm{MSE}=\frac{1}{N} \sum_{i=1}^{N}\left(x_{i}-y_{N}\right)^{2}$

$R=\frac{\sum_{i=1}^{N}\left(x_{i}-\bar{x}\right)\left(y_{i}-\bar{y}\right)}{\sqrt{\sum_{i=1}^{N}\left(x_{i}-\bar{x}\right)^{2}\left(y_{i}-\bar{y}\right)^{2}}}$

where $x_{i}, y_{N}, \bar{x}$ and $\bar{y}$ are the target value, the predicted output, the average of target values and the average of predicted output, respectively.

\subsection{ANN-GA optimisation technique}

The best ANN network structure considered as a surrogate model was then bridged to a genetic algorithm (GA) available in the optimisation toolbox of Matlab ${ }^{\circledR}$ software to determine the optimal FSD. The workflow of the coupled ANN-GA optimisation loop is shown in Fig. 8. This algorithm is an optimisation technique that belongs to the larger class of evolutionary algorithms, which is inspired by the process of natural selection. The algorithm works by repeatedly modifying a population of individual solutions identified as chromosomes. At each successive stage, the algorithm selects individuals from the current population based on their fitness and uses them as parent chromosomes to produce the next generation using genetic operators, viz. crossover and mutation. The method repeats until reaching the stopping criterion and an optimum solution is evolved. GA technique presents an important advantage, and it can be used to solve problems with a high non-linear relationship between process input parameters and output performances (i.e. the GA optimisation method is used to converge a global optimum among several possible local optimums [55]). In this work, the use of ANN-based surrogate model makes the fitness evaluation much cheaper compared to high time-consuming FE computations.

\section{Result and discussion}

\subsection{ANN model evaluation}

The building of a robust and accurate ANN model is mainly based on its topology since it can greatly influence the predicted MFB indexes. The number of neurons in the input and
Fig. 8 Workflow of the FSD with ANN-GA optimisation loop

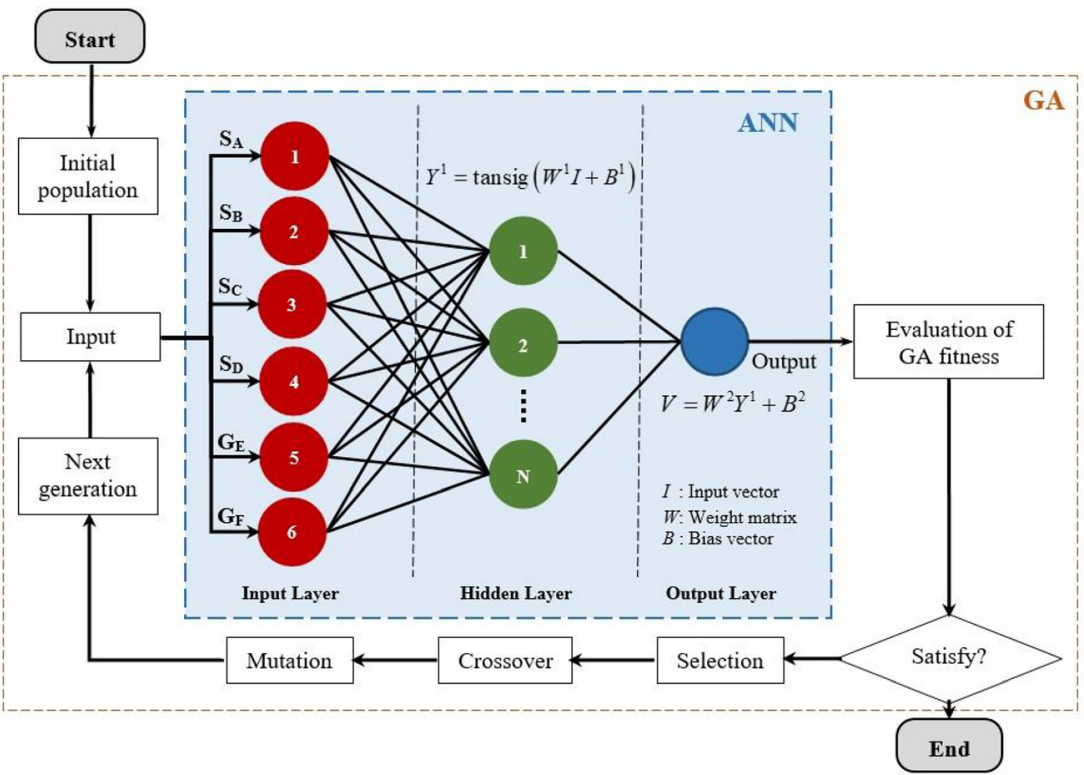


output layers is defined by the studied problem specification. However, the number of hidden layers and neurons has to be fine-tuned to have low bias and variance. One hidden layer ANN is chosen for this study. The number of neurons in hidden layer was recognised by training several ANN topologies and selecting the optimal one based on minimisation of MSE. First, the number of neurons in the hidden layer was examined for the two-studied training algorithm "trainlm" and "traingdx" to determine the optimal neuron number for the ANN models. It was found that the optimal neural number, for both training algorithms, is 18 and 14 respectively in the case of ingate velocity and jet high models. Second, both NN models with their best structure were tested for the remaining combinations of training algorithms and transfer functions as summarised in Table 3. Then, the ANN models are evaluated according to the statistical performance indices MSE and $R$. As expected in Table 3, it is obvious that MSE and correlation coefficient $(R)$ values depend on both training algorithm and transfer function. The best performances for the ingate velocity ANN model are found for trainlm training algorithm and tansig transfer function since it presents the lowest MSE value $\left(\mathrm{MSE}=1.18 \times 10^{-5} \mathrm{~m}^{2} \mathrm{~s}^{-2}\right)$. In addition, it provides a faster convergence in training phase compared to traingdx algorithm [56]. Table 3 also displays that the best neural network architecture for the jet high is found for the trainlm training algorithm and tansig transfer function since it presents the lowest MSE value of $0.04 \mathrm{~mm}^{2}$.

The predicted versus target results for training and test datasets are plotted in Fig. 9 for both studied outputs. This figure reveals a good fit quality between the target and the predicted data given by both NN models after training phase since they present a high correlation coefficient $\left(R_{\text {train }}\right.$ of 0.999 ), i.e. the closer the curve of predicted data to the target data, the higher the accuracy of the model.

The second phase of ANN modelling consists of testing the generalisation capability of both selected ANN models and verify if they can predict the studied MFB indexes of any new data not used in the training process. Hence, ANN models were simulated using test dataset and the correlation coefficient $R_{\text {test }}$ was calculated for both MFB indexes. It is obvious that generalisation capability is robust for both proposed ANN models given the high value of $R_{\text {test }}$. This outcome shows that twenty-five experiments are sufficient in practice to build valid ANN models to predict the ingate velocity and the jet high in the mould cavity during the first phase of filling stage in sand casting processes.

\subsection{FSD optimisation using genetic algorithm}

The developed NN models were used for optimisation by GA. The GA was designed to generate the best fitness function for each ANN model as presented in Fig. 8. Taguchi DoE ranges are set as bounds on the six input variables as given by Eq. 15 (all dimensions are in $\mathrm{mm}$ ) and one hundred individuals within the bounds are chosen in the initial population.

$$
\begin{aligned}
155 & \leq S_{\mathrm{A}} \leq 215 \\
19 & \leq S_{\mathrm{B}} \leq 27 \\
5 & \leq S_{\mathrm{C}} \leq 15 \\
12 & \leq S_{\mathrm{D}} \leq 20 \\
35 & \leq G_{\mathrm{E}} \leq 55 \\
5 & \leq G_{\mathrm{F}} \leq 15
\end{aligned}
$$

The numerical parameter values used in the GA options for the optimisation runs are enlisted in Table 4. In this optimisation, the rank method is applied for the fitness scaling, whereas stochastic uniform is utilised for the selection method in order to stipulate how the GA chooses parents for the next generation. From the 100 numbers of population size, two of

\begin{tabular}{|c|c|c|c|c|c|c|c|}
\hline \multirow[t]{2}{*}{$\begin{array}{l}\text { ANN } \\
\text { model }\end{array}$} & \multirow[t]{2}{*}{ Structure } & \multirow[t]{2}{*}{$\begin{array}{l}\text { Train } \\
\text { algorithm }\end{array}$} & \multirow[t]{2}{*}{$\begin{array}{l}\text { Transfer } \\
\text { function (HL) }\end{array}$} & \multirow[t]{2}{*}{$\begin{array}{l}\text { Performance } \\
\text { achieved (MSE) }\end{array}$} & \multicolumn{3}{|c|}{$\begin{array}{l}\text { Correlation coefficient } \\
(R)\end{array}$} \\
\hline & & & & & Train & Test & $\begin{array}{l}\text { All } \\
\text { data }\end{array}$ \\
\hline \multirow{4}{*}{$\begin{array}{l}\text { Ingate } \\
\text { velocity }\end{array}$} & \multirow[t]{4}{*}{ [6-18-1] } & \multirow[t]{2}{*}{ Trainlm } & $\tan s i g$ & $1.18 \times 10^{-5} \mathrm{~m}^{2} \mathrm{~s}^{-2}$ & 0.999 & 0.998 & 0.998 \\
\hline & & & logsig & $9.55 \times 10^{-5} \mathrm{~m}^{2} \mathrm{~s}^{-2}$ & 0.997 & 0.995 & 0.996 \\
\hline & & \multirow[t]{2}{*}{ Traingdx } & tansig & $1.34 \times 10^{-3} \mathrm{~m}^{2} \mathrm{~s}^{-2}$ & 0.983 & 0.937 & 0.979 \\
\hline & & & logsig & $2.96 \times 10^{-3} \mathrm{~m}^{2} \mathrm{~s}^{-2}$ & 0.952 & 0.864 & 0.938 \\
\hline \multirow[t]{4}{*}{ Jet high } & \multirow[t]{4}{*}{ [6-14-1] } & \multirow[t]{2}{*}{ Trainlm } & $\tan s i g$ & $0.04 \mathrm{~mm}^{2}$ & 0.999 & 0.996 & 0.998 \\
\hline & & & logsig & $0.81 \mathrm{~mm}^{2}$ & 0.976 & 0.998 & 0.984 \\
\hline & & \multirow[t]{2}{*}{ Traingdx } & $\tan s i g$ & $3.07 \mathrm{~mm}^{2}$ & 0.944 & 0.974 & 0.954 \\
\hline & & & $\log s i g$ & $13.70 \mathrm{~mm}^{2}$ & 0.819 & 0.987 & 0.863 \\
\hline
\end{tabular}
them are elite counts and are used in the next generation, whereas $80 \%$ of the remaining population is employed for
Table 3 Transfer function and training algorithm effect on ANN model performances 
Fig. 9 Predicted versus target values for the optimal ANN models for both studied MFB indexes $\mathbf{a}$ ingate velocity and $\mathbf{b}$ jet high
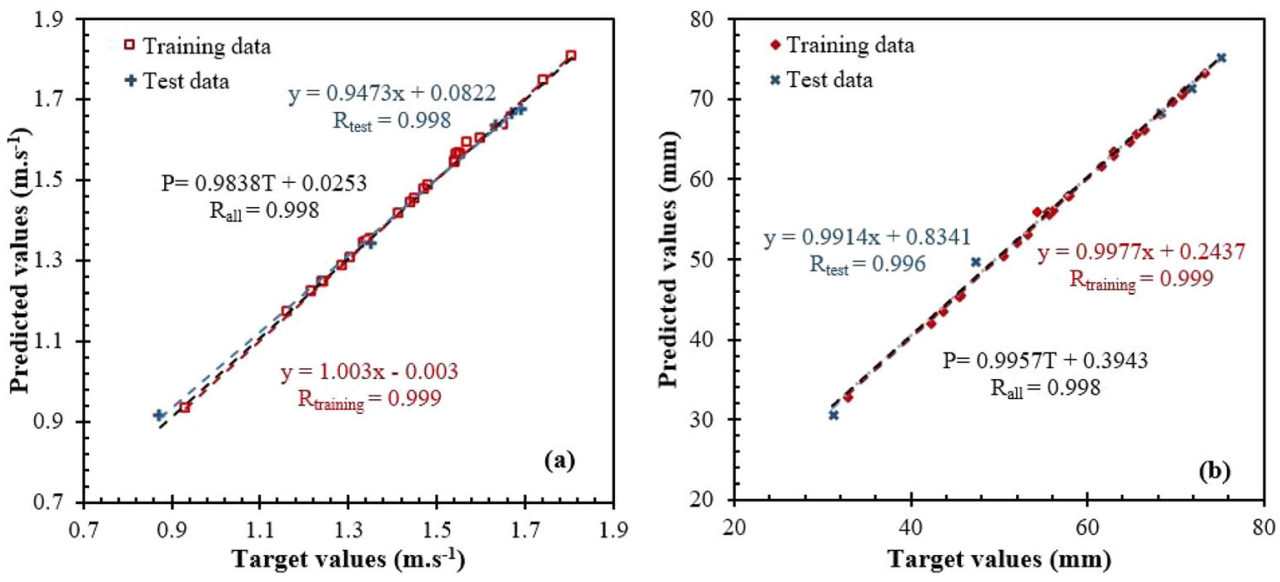

Table 4 Computational parameters of genetic algorithm used in FSD optimisation

\begin{tabular}{ll}
\hline Computational parameters & Values \\
\hline Population size & 100 \\
Elite count & 2 \\
Crossover fraction & 0.80 \\
Number of generations & 50 \\
Fitness scaling function & Rank fitness scaling \\
Selection function & Stochastic uniform \\
Crossover function & Scattered \\
Mutation function & Constraint dependent mutation function \\
Direction for migration & Forward with migration fraction set at 0.2 \\
Non-linear constrain algorithm & Augmented Lagrangian \\
\hline
\end{tabular}

the crossover reproduction and $20 \%$ is utilised for the mutation reproduction.

The evolution of the best and the mean fitness values with generations for both ANN-GA models is shown in Fig. 10. It is clear that convergence is reached, for the first model, after 11th generations (Fig. 10a). The best fitness value is stabilised at a value of $0.84 \mathrm{~m} \mathrm{~s}^{-1}$ for the best design parameters as shown in Fig. 11. It is obvious that design parameters $S_{\mathrm{A}}$, $S_{\mathrm{C}}, S_{\mathrm{D}}$ and $G_{\mathrm{E}}$ converged to the lower limit of their studied ranges. Inversely, $G_{\mathrm{F}}$ converged towards its upper studied range value. Finally, the design parameter $S_{\mathrm{B}}$ stabilised at $20.3 \mathrm{~mm}$. Before examining this result, it was crucial to test the validity of the proposed ANN-GA optimal solution with a FE simulation. It was found that the average value of the ingate velocity obtained by FE simulation was $0.89 \mathrm{~m} \mathrm{~s}^{-1}$, which is considered as fairly close to the ANN-GA predicted value $\left(V_{\text {ingate }}=0.84 \mathrm{~m} \mathrm{~s}^{-1}\right)$. The error between predicted and simulated values does not exceed $5.61 \%$.
Fig. 10 Fitness value evolution over generations for tested ANNGA models: a ingate velocity and b jet high
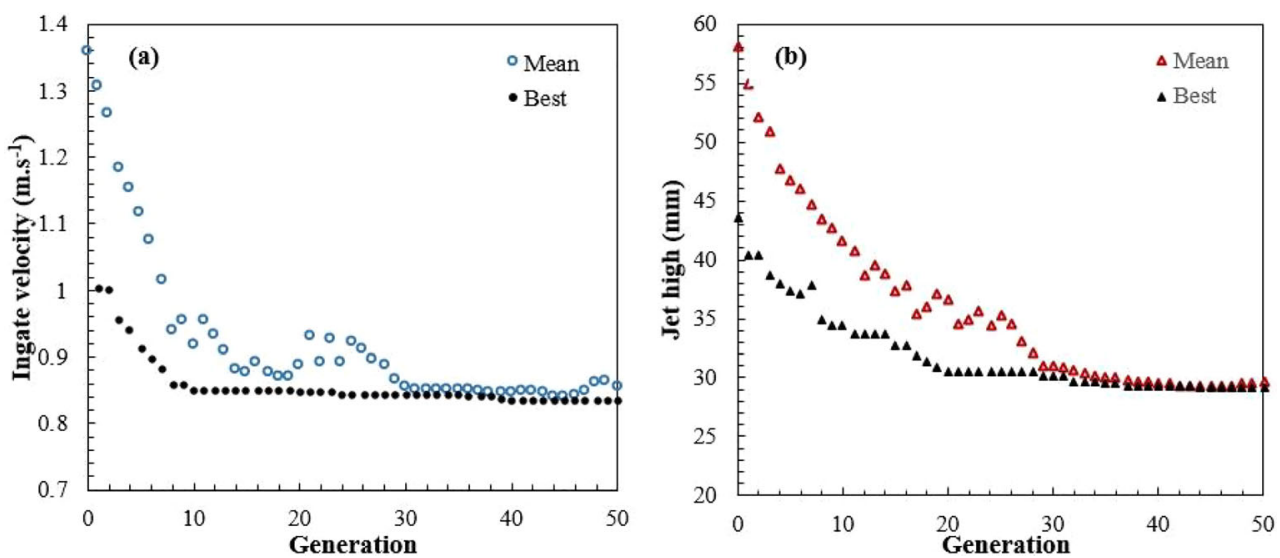
Fig. 11 Optimal FSD parameters obtained with ANN-GA models compared to the best FE simulation (case no. 26)

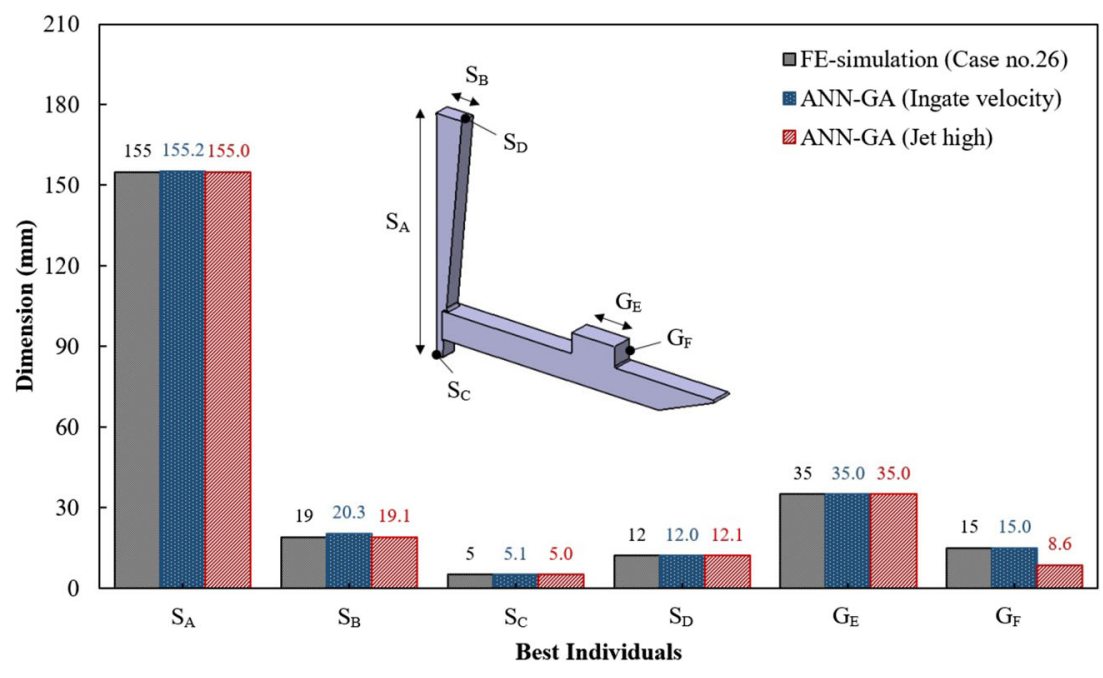

The FSD optimised by ANN-GA procedure is very close to the configuration of the case no. 26 used for testing ANN model, in which the ingate velocity presents its lowest value (Table 2). The only difference concerns the design parameter $S_{\mathrm{B}}$ that shall be equal to $19 \mathrm{~mm}$. For this case, the gating ratio is calculated in accordance with the filling system characteristic sections (sprue exit area, runner area and gate area) as shown in Table 5. It is found that the gating ratio is 1:4:7, which proves that the filling system is classified as unpressurised system. For such systems, the melt flow rate is mainly controlled by the area of the choke located at the base of the sprue (the bottom cross-section) [57]. This result can probably explain the convergence of the design parameter $S_{\mathrm{B}}$ by the optimisation loop to the value of 20.3 instead of $19 \mathrm{~mm}$. In other words, since the melt flow is always choked by the base of the sprue, the value of the ingate velocity appears to be very little sensitive to the design parameter $S_{\mathrm{B}}$, for all the studied domains, that could be the source of the observed difference in $S_{\mathrm{B}}$ calculation.

Concerning the second ANN model, the best fitness plot of the jet high is reached after more than 40 generations as shown in Fig. 10b. The jet high has a value of $29.21 \mathrm{~mm}$ for the optimal FSD. The error between the optimal ANN-GA predicted and FE simulated (case no. 26) jet high values does not exceed $6.31 \%$, which is considered as acceptable. However, in

Table 5 The area ratios of the optimal FSD predicted with ANN-GA ingate velocity model

\begin{tabular}{lllll}
\hline & Sprue entry & Sprue exit & Runner & Gate \\
\hline Area $\left(\mathrm{mm}^{2}\right)$ & 244 (top) & 60 (bottom) & 240 & 420 \\
Gating ratio & - & 1 & 4 & 7 \\
\hline
\end{tabular}

order to recognise the source of the gap observed in the value of the ingate high $\left(G_{\mathrm{F}}\right)$, which converges to $8.6 \mathrm{~mm}$ in ANNGA prediction instead of $15 \mathrm{~mm}$ in FE simulation (Fig. 11), the sensitivity of the ANN model to the design parameter $G_{\mathrm{F}}$ was analysed for this optimal case. It was found that the model sensitivity to the design parameter $G_{\mathrm{F}}$ is equal to $3.95 \%$. This result can explain the gap in the value of the ingate high $\left(G_{\mathrm{F}}\right)$, i.e. the model is little sensitive to the input parameter $G_{\mathrm{F}}$.

In view of above discussion, it is clear that both MFB indexes, the ingate velocity and the jet high, could be used in sand casting processes to optimise the FSD and control the melt flow in the mould cavity in order to improve the castings' quality. However, the use of the jet high as a MFB index seems to be more suitable for the present method. The use of jet high index presents the advantage that its determination from FE simulation is simpler and it is independent from the post-processing procedure, compared to the ingate velocity, as mentioned in the Section 2.3.

The proposed intelligent method, based on ANN-GA model, exhibits several advantages compared to traditional gradient-based methods. The use of an evolutionary algorithm permits to solve high non-linear problems and converge to a global minimum while gradient-based methods can get stuck in a local minimum since their performances are strongly depending on the initial values of the design variables $[18,55]$. In addition, the coupling of the GA with an ANN surrogate model, trained on a high-fidelity database, makes the evaluation of the fitness value not only more accurate than traditional methods but also much cheaper.

Finally, it should be observed that the paradigm presented in this study is generic and can be easily extended to suit other FSD shapes and sizes, with different casting alloys and casting processes. 


\section{Conclusion}

In this paper, the application of an intelligent optimisation method integrating ANN and GA soft computing techniques was proposed to optimise the FSD in sand casting processes. This approach has a peculiar merit that it is based on accurate FEM analysis and not on experimental data collection, which could be costly, time consuming and subject of error prone. The coupled 3D thermo-hydraulic modelling of the MFB inside the mould cavity during filling stage was performed, via ProCAST® FE software, and validated using experimental literature data. The validation procedure was carried out in two steps in order to verify the accuracy of the FE model from qualitative and quantitative point of view.

Two MFB indexes, namely ingate velocity and jet high, were determined based on $\mathrm{FE}$ computations for a combination of FSD parameters. The possibility to build a FFBP neural network that can be able to predict and optimise the FSD for each index was studied. The optimal network topology was determined by several experiments. The best-found structures for the ingate velocity and the jet high models are respectively 6-18-1 and 6-14-1. Levenberg-Marquardt training algorithm was selected to train both ANN models, and the activation functions tansig and purlin were chosen respectively for the hidden and the output layers. It was found that both ANN models could predict with a high accuracy the studied MFB indexes within the studied parameter domains.

The retained ANN models were coupled with GA to select the optimal FSD. The validity of the found solutions was tested by comparing ANN-GA prediction with FE computations for both studied MFB indexes. It was found that errors do not exceed $5.61 \%$ and $6.31 \%$ respectively for the ingate velocity and the jet high. This result proves that the proposed intelligent approach provides a very effective tool to optimise the FSD parameters in sand casting process. Furthermore, it was agreed that the use of jet high as a MFB index could be an interesting alternative of the ingate velocity in FSD optimisation.

\section{Code availability Not applicable.}

Author's contribution AK planned and carried out the simulations. AK and ME contributed to the analysis of the results and to the writing of the manuscript.

Data availability Not applicable.

\section{Declarations}

Ethics approval and consent to participate Not applicable.

Conflict of interest The authors declare no competing interests.

\section{References}

1. Bozchaloei GE, Varahram N, Davami P, Kim SK (2012) Effect of oxide bifilms on the mechanical properties of cast Al-7Si- $0.3 \mathrm{Mg}$ alloy and the roll of runner height after filter on their formation. Mater Sci Eng A 548:99-105

2. Sama SR, Badamo T, Lynch P, Manogharan G (2019) Novel sprue design in metal casting via 3D sand-printing. Addit Manuf 25:563578

3. Pradhan AR, Pattnaik S, Sutar MK (2019) Improving the filling system for a defect free casting: a review. Materials Today: Proceedings 18:2887-2892

4. Campbell J (1993) Invisible macro defects in castings. Journal de Physique IV The third European Conference on Advanced Materials and Processes C7:861-872.

5. Ruddle RW (1956) The running and gating of sand casting. Inst Met Monogr Rep Ser 19

6. Swift RE, Jackson JH, Eastwood LW (1949) A study of principles of gating. AFS Trans 57:76-88

7. Renukananda KH, Ravi B (2016) Multi-gate systems in casting process: comparative study of liquid metal and water flow. Mater Manuf Process 31(8):1091-1101

8. Cuesta R, Maroto JA, Morinigo D, De Castro I, Mozo D (2006) Water analogue experiments as an accurate simulation method of the filling of aluminum castings. Trans Am Foundrymens Soc 114: $137-150$

9. Kuo J, Huang P, Lai H et al (2017) Optimal gating system design for investment casting of 17-4PH stainless steel enclosed impeller by numerical simulation and experimental verification. Int J Adv Manuf Technol 92:1093-1103

10. Huang P, Lin C (2015) Computer-aided modeling and experimental verification of optimal gating system design for investment casting of precision rotor. Int J Adv Manuf Technol 79:9971006

11. Sun Z, Hu H, Chen X (2008) Numerical optimization of gating system parameters for a magnesium alloy casting with multiple performance characteristics. J Mater Process Technol 199(1-3): 256-264

12. Beckermann C (1992) Water modeling of steel flow, air entrainment and filtration, September, SFSA T\&O Conference.

13. Shaikh MBN, Ahmad S, Khan A, Ali M (2018) Optimization of multi-gate systems in casting process: experimental and simulation studies. IOP Conference Series: Materials Science and Engineering IOP Publishing 404 No 1.012040.

14. Sun W, Bates CE (2003) Visualizing defect formation in gray iron castings using real time X-rays. Trans Am Foundrymens Soc 111: 859-867

15. Juretzko FR, Stefanescu DM (2005) Comparison of mold filling simulation with high speed video recording of real-time mold filling. AFS Trans 113:1-11

16. Sama SR, MacDonald E, Voigt R, Manogharan G (2019) Measurement of metal velocity in sand casting during mold filling. Metals 9:1079

17. Ingle PD, Narkhede BE (2018) A literature survey of methods to study and analyze the gating system design for its effect on casting quality. Mater Today Proc 5:5421-5429

18. Ransing RS, Sood MP (2006) Optimization in castings - an overview of relevant computational technologies and future challenges. Metall Mater Trans B 37:905-911

19. Jezierski J, Dojka R, Janerka K (2018) Optimizing the gating system for steel castings. Metals 8(4):266

20. Esparza CE, Guerrero-Mata MP, Rios-Mercado RZ (2006) Optimal design of gating systems by gradient search methods. Comput Mater Sci 36:457-467 
21. Dučić N, Ćojbašić Ž, Manasijević S, Radiša R, Slavković R, Milićević I (2017) Optimization of the gating system for sand casting using genetic algorithm. Int J Metalcast 11:255-265

22. Kor J, Chen X, Hu H (2009) Multi-objective optimal gating and riser design for metal-casting, IEEE Control Applications, (CCA) \& Intelligent Control, (ISIC), St. Petersburg 428-433. https://doi.org/ 10.1109/CCA.2009.5280821

23. Chen WJ, Lin CX, Chen YT, Lin JR (2016) Optimization design of a gating system for sand casting aluminium A356 using a Taguchi method and multi-objective culture-based QPSO algorithm. Adv Mech Eng 8:1-14

24. Yang X, Din T, Campbell J (1998) Liquid metal flow in moulds with off-set sprue. Int J Cast Metal Res 11(1):1-12

25. Sama SR, Wang J, Manogharan G (2018) Non-conventional mold design for metal casting using 3D sand printing. J Manuf Process 34:765-775

26. Bedel M, Sanitas A, El Mansori M (2019) Geometrical effects on filling dynamics in low pressure casting of light alloys. J Manuf Process 45:194-207

27. Jiang WM, Fan ZT, Liu DJ, Liao DF, Zhao Z, Dong XP, Wu HB (2012) Influence of process parameters on filling ability of A356 aluminium alloy in expendable pattern shell casting with vacuum and low pressure. Int J Cast Metal Res 25:47-52

28. Jiang W, Fan Z, Liu D, Wu B (2013) Influence of gas flowrate on filling ability and internal quality of A356 aluminum alloy castings fabricated using the expendable pattern shell casting with vacuum and low pressure. Int J Adv Manuf Technol 67:2459-2468

29. Sirrell B, Holliday M, Campbell J (1996) Benchmark testing the flow and solidification modeling of Al castings. JOM 48(3):20-23

30. Jiaqi W, Paixian F, Hongwei L, Dianzhong L, Yiyi L (2012) Shrinkage porosity criteria and optimized design of a 100-ton 30Cr2Ni4MoV forging ingot. Mater Des 35:446-456

31. Ravindran K, Lewis RW (1998) Finite element modelling of solidification effects in mould filling. Finite Elem Anal Des 31(2):99116

32. Lewis RW, Ransing RS (2000) The optimal design of interfacial heat transfer coefficients via a thermal stress model. Finite Elem Anal Des 34:193-209

33. Gethin DT, Lewis RW, Tadayon MR (1992) A finite element approach for modelling metal flow and pressurised solidification in the squeeze casting process. Int J Numer Methods Eng 35:939-950

34. Swaminathan CR, Voller VR (1994) A time-implicit filling algorithm. Appl Math Model 18(2:101-108

35. Postek EW, Lewis RW, Gethin DT (2008) Finite element modelling of the squeeze casting process. Int J Numer Method H 18(3/4): 325-355

36. Mondy L, Rao R, Brooks C et al. (2007) Wetting and free surface flow modeling for potting and encapsulation, Sandia National Laboratories Albuquerque, New Mexico 87185 and Livermore, California 94550.

37. Baoguang S, Xiuhong K, Dianzhong L (2010) A novel technique for reducing macrosegregation in heavy steel ingots. J Mater Process Technol 210:703-711

38. Nastac L, Stefanescu DM (1996) Macrotransport-solidification kinetics modeling of equiaxed dendritic growth: part II. Computation problems and validation on INCONEL 718 superalloy castings. Metall Mater Trans A 27:1996-4075
39. ProCast User Manual Version 2009 (2009) 1. ESI group. The virtual try-out space company

40. Valencia JJ, Quested PN (2008) Thermophysical properties, ASM handbook: casting ASM Handbook Committee 15:468-481.

41. Sun HC, Chao LS (2009) An investigation into the effective heat transfer coefficient in the casting of aluminium in a green-sand mold. Mater Trans 50(6):1396-1403

42. Assael MJ, Kakosimos K, Banish RM, Brillo J, Egry I, Brooks R, Quested PN, Mills KC, Nagashima A, Sato Y, Wakeham WA (2006) Reference data for the density and viscosity of liquid aluminum and liquid iron. J Phys Chem Ref Data 35:285-300

43. Ktari A, El Mansori M (2020) Digital twin of functional gating system in $3 \mathrm{D}$ printed molds for sand casting using a neural network. J Intell Manuf. https://doi.org/10.1007/s10845-020-01699-3

44. Levy PS, Lemeshow S (2013) Sampling of populations: methods and applications. Wiley, Hoboken

45. Robbins H (1985) Some aspects of the sequential design of experiments, Herbert Robbins Selected Papers. Springer, Berlin, pp 169 177

46. Marshall MN (1996) Sampling for qualitative research. Fam Pract 13(6):522-526

47. Montgomery DC (2017) Design and analysis of experiments. Wiley, Hobo-ken

48. Roy RK (2001) Design of experiments using the Taguchi approach: 16 steps to product and process improvement. Wiley, New York

49. Campbell J (2015) Complete casting handbook: metal casting processes, metallurgy, techniques and design, 2nd edn. ButterworthHeinemann, Oxford

50. Gnana SK, Deepa SN (2013) Review on methods to fix number of hidden neurons in neural networks. Math Probl Eng 6. https://doi. org $/ 10.1155 / 2013 / 425740$

51. Awolusia TF, Oke OL, Akinkurolere OO et al (2019) Performance comparison of neural network training algorithms in the modelling properties of steel fiber reinforced concrete. Heliyon 5. https://doi. org/10.1016/j.heliyon.2018.e01115

52. Adeoti O, Osanaiye PA (2013) Effect of training algorithms on the performance of ANN for pattern recognition of bivariate process. Int J Comput Appl 69:8-12

53. Coskun N, Yildrim T (2003) The effects of training algorithms in MLP network on image classification, in Proc. Int Joint Conf on Neural Netw 2:1223-1226

54. Khayet M, Cojocaru C (2012) Artificial neural network modeling and optimization of desalination by air gap membrane distillation. Sep Purif Technol 86:171-182

55. Golberg DG (1954) Genetic algorithms in search, optimization and machine learning. Addison-Wesley Publishing Company Inc., Boston ISBN: 978-0-201-15767-3

56. Demuth H, Beale M (1996) Matlab Neural Network For Use with MATLAB, User's Guide, Version 4, The Math Works, Inc.

57. Johnson FH, Eyring H, Polissar MJ (1954) The kinetic basis of molecular biology J, vol 286. Wiley \& Sons, Inc, New York

Publisher's note Springer Nature remains neutral with regard to jurisdictional claims in published maps and institutional affiliations. 